\title{
Review of Studies on the Last Enzymes in Bacteriochlorophyll (Bchl) and Chlorophyll (Chl) Biosynthesis
}

\author{
Silvio M. D. Nascimento, Yuanyuan Zou, Qi Cheng* \\ Biotechnology Research Institute, Chinese Academy of Agricultural Sciences, Beijing, China \\ Email: "chengqi@vip.126.com
}

Received 22 June 2016; accepted 21 August 2016; published 24 August 2016

Copyright @ 2016 by authors and Scientific Research Publishing Inc.

This work is licensed under the Creative Commons Attribution International License (CC BY). http://creativecommons.org/licenses/by/4.0/

(c) (7) Open Access

\section{Abstract}

This paper summarizes the information available online related to mechanisms of Chlorophyll and Bacteriochlorophyll biosynthesis, emphasizing four enzymes in its last steps. The biosynthesis of Chlorophyll (ChI)/Bacteriochlorophyll $(B c h l)$ is essential for the occurrence of photosynthesis. Four enzymes catalyze parts of the last chemical reactions steps to biosynthesize $\mathrm{Bchl} / \mathrm{Chl}$; they are: The Light-Dependent Protochlorophyllide (Pchlide) Oxidoreductase (LPOR: EC 1.3.1.33), the Light-Independent Pchlide oxidoreductase (DPOR: EC 1.3.7.7), Chlide Reductase (COR: EC 1.3.99.35) and the Divinyl Reductase (DVR: EC 1.3.1.75). These enzymes catalyze the reductions reactions of tetrapyrrole's rings in the Chlorophyll and Bacteriochlorophyll biosynthesis process. This review has the aim to organize, analyze and compare the most important discoveries related to these four enzymes discovered so far. The comparisons are made with the information from the bibliography used, and the sequence of these enzymes got from online database. Sequence alignment, phylogenetic and molecular evolutionary analysis of all the four enzymes was conducted to find their levels of similarities.

\section{Keywords}

Photosynthesis Chlorophyll, Bacteriochlorophyll Biosynthesis, Enzymes DVR, DPOR, LPOR and COR

\section{Introduction}

There is no consensus about when the process of Photosynthesis started. There are a number of different lines of

"Corresponding author.

How to cite this paper: Nascimento, S.M.D., Zou, Y.Y. and Cheng, Q. (2016) Review of Studies on the Last Enzymes in Bacteriochlorophyll (Bchl) and Chlorophyll (Chl) Biosynthesis. American Journal of Plant Sciences, 7, 1639-1651. 
evidence which point to an origin: Carbon isotope data, other chemical evidence and the recent fossil record [1] [2]. They all indicate that the process of photosynthesis originated early in Earth's history, more than 3 billion years ago. They each suggest that photosynthesis evolved to its current mechanistic diversity and phylogenetic distribution by a complex, nonlinear process. Photosynthesis is the processes responsible for the evolution of life, by converting photons of light, the basic source of energy that "feed" the process of photosynthesis, into chemical potential energy. It is dependent on a conserved $\mathrm{NADPH}_{2}$, ATP and light-capturing made by the pigments Bacteriochlorophyll $(B c h l) / C h l o r o p h y l l ~(C h l)$, which are the primary electron donors that drive the conversion of light into chemical energy to be conserved in $\mathrm{NADPH}_{2}$ and ATP [3]. These pigments are incorporated within antenna complexes of plants, algae and phototrophic bacteria, including also other apparatus as electron transfer complexes protein-pigment complexes known as reaction centers and carbon fixation machinery, allowing the harvest of the light energy, and perform photochemical reactions that lead to stable charge separation [1] [4]-[6]. Structural modifications to the tetrapyrrole macrocycle, that has four pyrrole rings (designated A to E) which are ligated into a tetrapyrrole ring with a magnesium atom in the center having the ring D esterified with phytol, are responsible for the specific absorption and energy-transfer features of the light-harvesting apparatus, influencing both pigment-pigment and pigment-protein interactions within the antenna complexes [7] [8]. The Bchl biosynthetic pathway is multibranched and represents the template of a Chl-protein biosynthesis center where photosystem (PS) I, PSII, and light-harvesting Chl-protein complexes are assembled into functional photosynthetic units [9]. The $C h l$ and Bchl biosynthetic pathway from protoporphyrin IX to Chl begins with the insertion of the $\mathrm{Mg}^{2+}$ ion [10]-[12]. After insertion of the $\mathrm{Mg}^{2+}$ ion in the tetrapyrrole structure, the enzyme "magnesiumprotoporphyrin methyltransferase" esterifies the propionic side chain of ring C in preparation for the cyclization reaction that produces ring $\mathrm{E}$ [12]. These rings are synthesized in the Chloroplast from eight molecules of 5-aminolevulinic acid. The porphyrin ring with its conjugated double bonds is assembled in the Chloroplast from eight molecules of 5-aminolevulinic acid, a highly reactive nonprotein amino acid (5-amino, 4-keto pentanoic acid) [3]. The spectral range of these complexes is extended by modifications, Bchls absorb at longer wavelengths than Chls [13]. Modifications as presence of ethyl and vinyl groups, can extend or confine the delocalized $\pi$-electron system of the Bchl macrocycle [14] to the Bchl macrocycle, which influence pigment-pigment and pigment-protein interactions within the antenna complexes [15]-[17]. Data shows that these parts have not had the same evolutionary history in all organisms. Therefore, the photosynthetic apparatus is best viewed as a mosaic made up of a number of substructures each with its own unique evolutionary history where the evolutionary histories of the various classes of antenna/light-harvesting complexes appear to be completely independent [2]. The transition from anoxygenic to oxygenic photosynthesis took place when the cyanobacteria started to use water as an electron donor for carbon dioxide reduction [2], marking a key point, and perhaps the point of the origin of the Photosynthesis process. Only later, when a predecessor to modern cyanobacteria acquired the ability to synthesize singly reduced pigments did Chl appear first serving as an antennae pigment (Chlorins in the antennae of modern Chlorobium) and later as a component of the reaction center [13]. Protochlorophyllide (Pchlide) is known as the main metabolite for the biosynthesis of Chl and Bchls [6]. Traveling through the evolution process of the photosynthetic organisms, analyzing the $C h l$ and the Bchl biosynthesis last steps, starting from Protoporphyrin IX, which is marked by the introduction of $\mathrm{Mg}$ metallocluster, the first enzyme (of those studied in this work) to find is the: Divinyl Reductase (DVR), that can be find in the enzyme databases with the Enzyme entry number: "EC 1.3.1.75"; then Light-Dependent Protochlorophyllide oxidoreductase (LPOR: EC 1.3.1.33); Light-Independent (dark-operative) Protochlorophyllide oxidoreductase (DPOR: EC 1.3.7.7) and the last one is the Chlorophyllide a Reductase (COR: EC 1.3.99.35). This group of enzymes participate in these reducing steps reactions in different rings. The DVR converts the divinyl Chlorophyllide a (Chlide a) to Monovinyl Chlide a [9] [18]. After the action of $D V R$, the next step is the production of Chlide from Pchlide, which involves the reduction $C_{17}=C_{18}$ in the D-ring (Figure 1) of the Mg-tetrapyrrole intermediate, Pchlide [19] [20]. There are two homologous enzymes that do the same work, but in different light conditions, one of these homologous is Light-Dependent "LPOR" [21], which requires light for catalysis, and the other one is the Light-Independent "DPOR” [22], which operates in absence of light. These steps are shared with Bchl, having all phototrophs (except angiosperms that have only $L P O R$, and anoxygenic bacteria, Photosynthetic bacteria having only DPOR), to form respectively $C h l$, and Bchl. Bchl, that differs from $C h l$ in the substituent rings A and B. The enzyme COR, is the last of these four enzymes of this study enter in action, which is specific of bacterio phototrophics (purple and green eubacteria). COR (called also CAO), perform the additional step that differentiate Bchl from Chl, the stereo-specific reduction of $C_{7}=C_{8}$ in the $\mathrm{B}$ ring (Figure 1), this is chemically similar to the $\mathrm{D}$ ring reduction of 


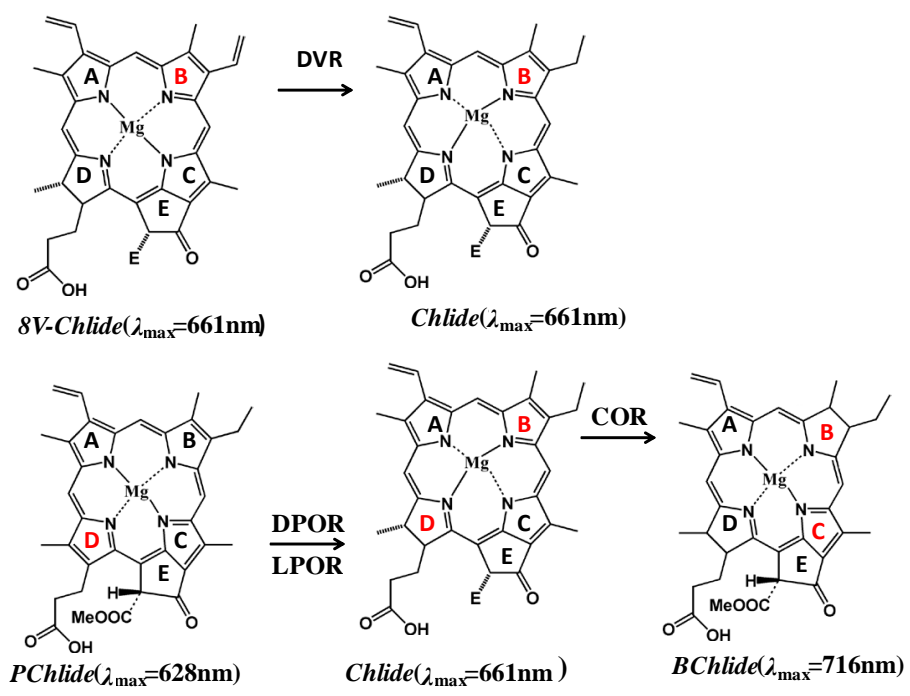

\begin{abstract}
Figure 1. Schematic representation of sections (8V-Chlide; Pchlide; Chlide and Bchlide) of thetetrapyrrole macrocycle reduction reactions of $C h l$ and $B C h l$ biosynthesis, where the each enzymes ( $D V R, D P O R, L P O R$ and $C O R)$ perform, with their respective wavelength of light absorption, adapted from Tsukatani et al. [64] and Burke et al. [13]. The arrows represent the names of the enzyme complexes (DVR, DPOR, LPOR and COR). The letters $\mathrm{A}, \mathrm{B}, \mathrm{C}, \mathrm{D}$ and $\mathrm{E}$ indicates the reductases substrates tetrapyrrole rings. The red letters in the ring show the rings where the respectives enzymes work.
\end{abstract}

Pchlide to form Chlide [23]. All this information about these enzymes has been put together in this paper. We have compared them with each other, summarized the most important discoveries to date, sequenced alignments and conducted phylogenetic and molecular evolutionary analysis of all the four enzymes.

\title{
1.1. Di-Vinyl Reductase (DVR)
}

This enzyme can be found with different denomination: Di-Vinyl Reductase; Divinyl Chlorophyllide a 8-Vinyl Reductase or $4 V C R$ [4-Vinyl] Chlorophyllide a Reductase, but here in this work it will be just " $D V R$ ". DVR converts divinyl chlide $a$ to monovinyl chlide $a$ in the Chl biosynthetic route [9] [18]. The ethyl group at the C8 position (8E) of the macrocycle is produced by the reduction of a vinyl group (8V), catalyzed by an $8 \mathrm{VR}$ (8Vinyl reductase; EC 1.3.1.75), resulting in the production of an $8 \mathrm{E}$ pigment [17]. The $D V R$ is divided into two types of unrelated enzymes (Figure 1), one in plant reductases, BciA belonging to the SDR family [24], and also having a ligand-binding site using $N A D P H$ as electron donors. And the other enzyme, which is in cyanobacterial reductases: $B c i B$ which uses ferredoxin as an electron donors and is present in some organisms belonging to Chlorobia, cyanobacteria, eukaryotes and Proteobacteria. BciB has high homology with coenzyme F420-reducing hydrogenase only found in methanogenic archaea [25]-[27]. The BciB tree is one of the few cases where Chloroflexi and Chlorobia are not sister groups, with Chloroflexi, closer to Allochromatium vinosum and Chloracidobacterium thermophilum sequences. Also, $B c i B$ shows separation between the major proteobacterial clade and the other photosynthetic taxa [28]. The orthologous (BciA and BciB) genes form a well-supported clade that can be subdivided into two groups, one comprising GSB and Proteobacteria sequences and another with cyanobacteria and eukaryotic sequences. The only exception is the Acaryochloris marina sequence that clusters within the proteobacterial clade. Because of the broad distribution of $N A D(P) H$-binding sites (Rossmann folds "GxGxxG") in proteins, database searching retrieved many additional hits, namely at the lower part of the tree [28], but in the protein alignment here for the phylogenetic trees, the $D V R$, and the other nitrogenase-like enzymes, showed no significant presence of Rossmann folds, except in the case of the $L$ subunit (DPOR).

\subsection{Light-Dependent Protochlorophyllide Oxidoreductase (LPOR)}

In the Chl biosynthesis, the final reaction that differentiates the angiosperms from the rest of the photosynthetic organisms [3] forms the chlorine structure of Chla at the Pchlide. This step is a key regulatory step in the Chl 
biosynthetic pathway in plants and bacteria, which has been extensively studied [21] [29]-[33]. This reaction is performed by the enzyme: Light-Dependent Protochlorophyllide (Pchlide) Oxidoreductase (LPOR: EC 1.3.1.33), also named $N A D P H$-Pchlide Oxidoreductase, which catalyzes the light-dependent trans addition of a hydrogen from $N A D P H$ to the carbon atom carrying the propionic side across the stereo-specific reduction of the $C_{17}=C_{18}$ double bond of the ring D (Figure 1) of Pchlide to produce Chlide [21] [29] [33]. This reaction, requires both light (absorption maximum 638 - $650 \mathrm{~nm}$ ) and NADPH for activity [3] [21] [34]. The LPOR polypeptide binds both $N A D P H$ and Pchlide, but the reduction does not occur until the protochlorophyllide molecule absorbs light at $628-630 \mathrm{~nm}$ [35]. LPOR is composed of a single polypeptide that belongs to Short-chain Dehydrogenase/ Reductase (SDR) family [30] [33]. LPOR is the enzyme responsible for the greening of angiosperms and is the only Pchlide reductase to operate in angiosperms [21] [31] [32] [36]. This starts to act when triggered by light, and plays an important regulatory role in angiosperm development, since it functionally acts as a gate in the biosynthetic pathway allowing Chl synthesis only when the plant is illuminated [37]. According to Yang \& Cheng [38] the LPOR gene originated in the cyanobacterial genome before the divergence of eukaryotic photosynthetic organisms, and the photosynthetic eukaryotes obtained their LPOR homologues through endosymbiotic gene transfer proving the finding of Suzuki \& Bauer [37], which defended that LPOR evolved before the advent of eukaryotic photosynthesis and that $L P O R$ did not arise to fulfill a function necessitated either by the endosymbiotic evolution of the chloroplast or by multicellularity; rather, it evolved to fulfill a fundamentally cell-autonomous role. Based on the protein sequence alignments, Wilks and Timko [30] identified two conserved residues (Tyr-275 and Lys-279) within the active site of the enzyme and also showed that they are critical foractivity of $L P O R$.

\subsection{Light-Independent Protochlorophyllide Oxidoreductase (DPOR)}

Dark-operative (or Light-Independent) Pchlide Oxidoreductase (DPOR: EC 1.3.7.7) is the other enzyme that is involved in the reduction of the penultimate step of Bchl/Chlbiosynthesis, [39], DPOR catalyzes the same stereo-specific reaction of $C_{17}=C_{18}$ double bound of Pchlide ring D (Figure 1) to form Chlidea absence of light [31] in oxygenic photosynthetic organisms [40]. Genetic and sequencing studies have showed that DPORwas first studied in purple bacteria [10] [41], where it was recognized to be essential for synthesis of Bchl in the dark. $D P O R$ is a nitrogenase-like enzyme with three subunits $B, L$ and $N$ [32] [35] [40]-[45], that code for putative subunits of the DPOR [11] [42], which are encoded by $B c h l$ genes ( $B c h B, B c h L$, and $B c h N)$ in photosynthetic bacteria genomes or by the ortholog Chlgenes $(C h l B, C h l L$, and $C h l N)$ in the plastid genomes of photosynthetic eukaryotes. These subunits are divided into two protein complexes, theL-protein (BchL/ChlL homodimer), a reductase component and an ATP dependent reductase specific for other catalytic component.The other complex is denominated NB-proteincomplex (a BchN-BchB/ChlN-ChlB heterotetramer), which provides the catalytic centers for the double-bond reduction of the Pchlide D-ring [23] [43] [44] [46]. It has already been demonstrated that ChlN and ChlB proteins are soluble and provide the catalytic site for the Pchlide reduction, and each NB-protein provides the catalytic sites for Pchlide reduction and carries a pair of $4 \mathrm{Fe}-4 \mathrm{~S}$ clusters that would mediate between the cluster of $L$-protein and Pchlide [47]. This cluster called "NB-cluster" is unique because it is coordinated by three Cysteine (Cys) residues from $B c h N\left(B c h N-C y s_{26}, B c h N-C y s_{51}, B c h N-C y s_{112}\right)$ and one Aspartic Acid (Asp) residue from $B c h B\left(B c h B-A s p_{36}\right)$. DPOR is distributed widely in the photosynthetic organisms since primitive anoxygenic photosynthetic bacteria as the sole photosynthetic enzyme [48]. It is also found in cyanobacteria, algae, mosses, liverworts, and gymnosperms. In each of these organisims DPOR has the company of its homologous LPOR to reduce the $C_{17}=C_{18}$ double bound [3] [32] [46]. DPORis considered a unique iron-sulphur enzyme that forms substrate radicals followed by sequential proton and electron-transfer steps [33]. The catalytic mechanism of DPOR includes the electron transfer from a "plant-type" [2Fe-2S] ferredoxin onto the dimeric DPOR subunit, BchL, carrying an intersubunit [4Fe-4S] redox center coordinated by $C_{9 S_{97}}$ and Cys $_{131}$ in Chlorobaculum tepidum. Wätzlich et al. [49], showed that in DPOR were found Lys $_{10}$ in the phosphate-binding loop (P-loop) and $\mathrm{Leu}_{126}$ in the switch II region, what is essential for DPOR catalysis and analogous to nitrogenase. Electrons from the $4 \mathrm{Fe}-4 \mathrm{~S}$ cluster of $B c h N B / C h I N B$ are transferred directly onto the Pchlide substrate at the active site of DPOR [49]. Evolutionary studies say that DPOR has been disappearing in the evolution pathway of plants, from gymnosperms to angiosperms [31] [32] [50]-[55]. According to [56] one of the reasons may be the low temperature, this has not been confirmed experimentally so far, and the fact that light-dependent pathways reduce Pchlide which may confer a selective advantage in certain environments for 
angiosperms. Some authors [43] [57] [58] suggest that the ChlL protein is associated with membranes and that it may function as an adenosine triphosphate-dependent electron donor, and Reinbothe et al. [22] suggests the $L$-protein of DPOR might function to sense the partial oxygen pressure in response to the light environment, thus providing a molecular tool to switch from oxygen-sensitive to oxygen-insensitive Pchlide reduction, confirming again this oxygen sensibility of the $D P O R$, specifically the $L$-protein subunit. NB-protein is stable in an aerobic condition [47]. Crystal structures of the DPOR components show that the shortest distance between an $N B$-cluster and Pchlide is $10.0 \AA$, which is close enough for permitting the through-space electron transfer reaction [59]. A primary, single electron transfer from the $4 \mathrm{Fe}-4 \mathrm{~S}$ cluster of $L$-protein to NB-cluster of NB-protein occurs and it is similar to that from the $4 \mathrm{Fe}-4 \mathrm{~S}$ cluster of Fe-protein to the P-cluster of MoFe-protein in the nitrogenase complex [43] [60]. The activity of DPOR is dependent upon both ATP hydrolysis and a reductant, which is most likely ferredoxin in vivo, and also dependent on the reductant dithionite [43] [44]. Crystallographic analysis of L-protein and NB-protein complex from Prochlorococcus marinus suggested that a water molecule just above $C_{18}$ is the direct proton donor for $C_{18}$ rather than the $C_{17}$-propionate in the Prochlorococcus NB-protein [61], however contribution of the water molecule has not yet been experimentally proven to be critical for Pchlide reduction in the Prochlorococcus DPOR. Results obtained so far in Rodobacter capsulatus DPOR support the reaction mechanism of the $C_{17}$-propionate as the proton donor to $C_{18}$ [33].

\subsection{Chlorophyllide $a$ Reductase (COR)}

In most photosynthetic organisms, the chlorin ring structure of Chla is formed by the reduction of the porphyrin $D$-ring by the DPOR. Subsequently, the chlorine ring B (Figure 1) is reduced in Bchl biosynthesis to form 3-vinyl bacteriochlorophyllide which has a bacteriochlorin ring structure [23]. This reduction is made by the enzyme: Chlide Reductase (COR: EC 1.3.99.35) which has three subunits: $b c h X, b c h Y$ and $b c h Z$ [53], and reduces the $C_{7}=C_{8}$ double bond of Chlide [62]. According to Nomata et al. [23] structural changes in COR have special effects on the spectral properties of these compounds enabling them to absorb infrared light to perform anoxygenic photosynthesis.COR from the bacterium Rhodobacter capsulatus is described to be able to also reduce the $8 \mathrm{~V}$ group of Chlidethus considered the third class of $8 V R(D V R)$, referred as a COR-type reductase [62]. $R$. capsulatus also contains an orthologue of $B c i A$ (the translated sequence of which is $61 \%$ identical and $72 \%$ similar to BciA from $R$. sphaeroides). It is likely that organisms with $8 E$-BChls use COR to reduce the $8 \mathrm{~V}$ group of any Chlide molecule that has bypassed the conventional 8VR. This mechanism may also account for the lack of any $B c i A$ or $B c i B$ orthologues in the genomes of $8 E$ BChla-producing Roseiflexus species [63] of green non-sulfur bacteria.

\subsection{Similarities between These Enzymes}

The DPOR and the COR enzymes show the most similarities with each other (Table 1), both convert porphyrin (Pchlide) to bacteriochlorin (3-vinyl Bchlide a) in Bchl a biosynthesis [47] and both are composed of three subunits [40]. In the amino acid sequence alignments of $B \operatorname{ch} X$ proteins and the closely related Bchlor ChlL subunits of $D P O R$, both cysteinyl ligands responsible for $4 \mathrm{Fe}-4 \mathrm{~S}$ cluster formation and residues for ATP binding are conserved [65]. Wätzlich et al. [49] presents, that $C O R$ subunit $B c h X$ forms a redox-active inter subunit cluster analogous to that described for DPOR subunits of Bchlor ChlL. In addition, the Tyrosine $\left(T y r_{127}\right)$ is proved to be essential for DPOR catalysis, where this surface-exposed residue is directly involved in protein-protein interaction and is responsible for the inter subunit electron transfer [49]. Gene duplication of an ancient reductase gave rise to a nitrogenase (NifH) and a Bchl/Chl branch. This ancient reductase (Chl/Bchl) of the Bchl/Chl path has thus evolved into the current $B \operatorname{ch} X_{2}$ and $B c h L_{2} / C h l L$ proteins. This evolutionary process came along with the appearance of subunits $B c h N B / C h l N B$ and $B c h Y Z$, responsible for the specific reduction of rings $B$ and $D$, respectively [49]. $B c h X$ and $B c h L$ share $34 \%$ amino acid sequence identity [53], also proved by the phylogenetic tree (Figure 2) where the two subunits are close to each other. Relatively to COR, which is also very similar related to DVR (Table 1), is also what was expected after know that it is able to reduce the $8 \mathrm{~V}$ group of Chlide, because of that is being considered the third class of $D V R$ [62]. Anaerobic conditions are required for the maximum activity of DPOR to complement the loss of LPOR [66]. Analysis of DPOR and LPOR enzymatic activity, in a variety of species, has demonstrated several functional differences in these enzymes, showing that coordination and regulation of DPOR and LPOR activity are responsive to environmental conditions, which allow the 


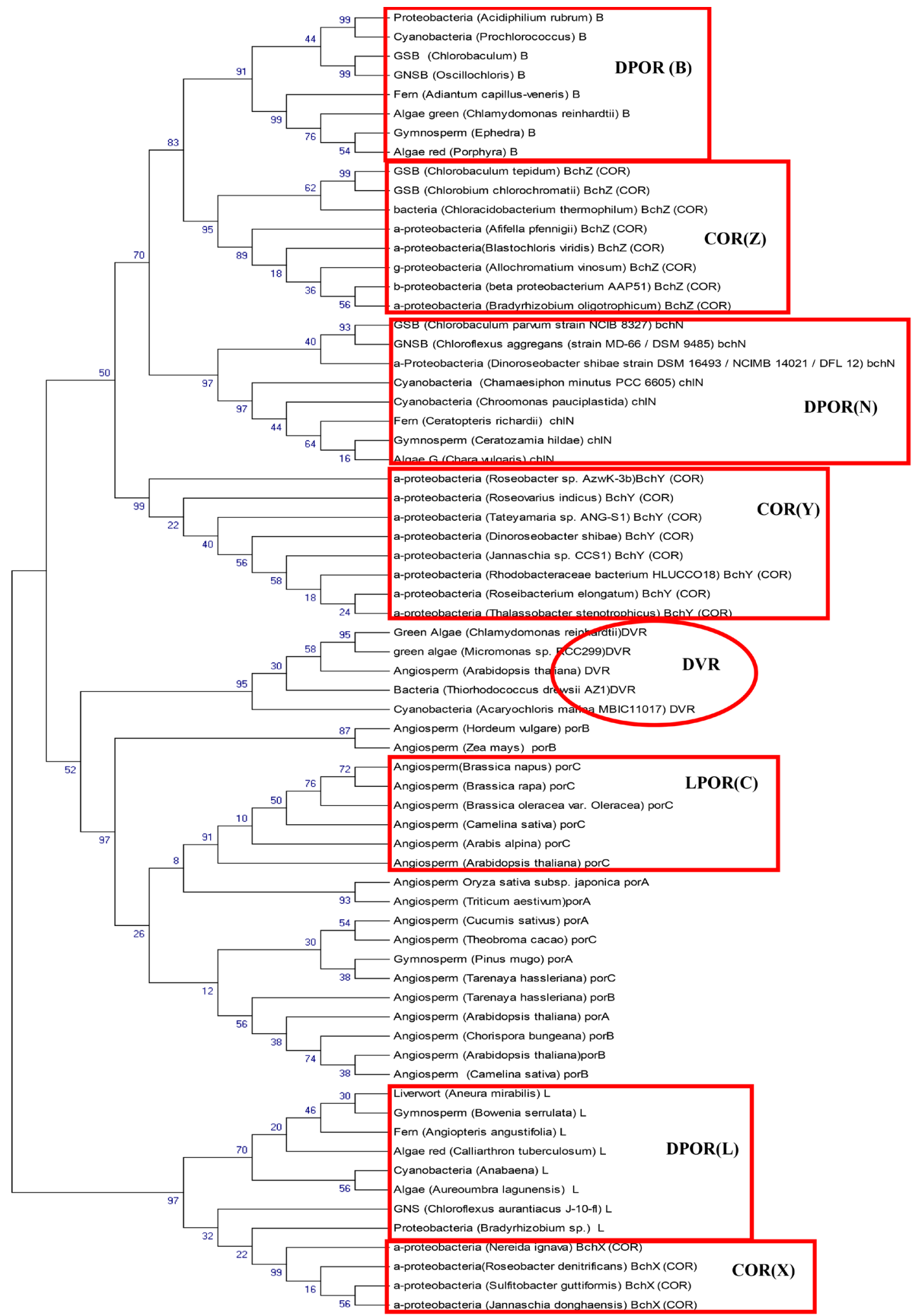

Figure 2. This Phylogenetic tree has 68 sequences divided in all 4 enzymes together DPOR subunits $(B, L$ and $N), C O R(X, Y$ and $Z$ ), DVR and LPOR (porA, porB and porC). This tree was generated using the neighbor-joining method after the alignment was made using MUSCLE also from the software package of MEGA6 [78]. 
Table 1. Resume of some information of these for enzymes.

\begin{tabular}{|c|c|c|c|c|c|c|}
\hline Enzyme & Oxygen & Light & Types & Encoded & Cofactor & Present in \\
\hline $\begin{array}{c}\text { COR } \\
\text { (EC .3.99.35) }\end{array}$ & Sensitive & Independent & $\begin{array}{c}B \operatorname{ch} X, B \operatorname{ch} Y \text { and } \\
B \operatorname{chZ}\end{array}$ & Chloroplast & $\begin{array}{l}\text { ATP; NADPH; } \\
\text { [Fe-S] }\end{array}$ & NS bacterium \\
\hline $\begin{array}{c}\text { DVR } \\
\text { (EC 1.3.1.75) }\end{array}$ & Sensitive & Independent & $B c i A$ and $B c i B$ & $\begin{array}{l}\text { Chloroplast } \\
\text { (etioplast) }\end{array}$ & $\begin{array}{l}\text { [4Fe-S]; FAD; } \\
\text { NADPH }\end{array}$ & All Phototrophs \\
\hline $\begin{array}{c}\text { DPOR } \\
\text { (EC 1.3.7.7) }\end{array}$ & Sensitive & Independent & $\begin{array}{l}\text { (subunits): } \\
\text { BchB/ChlB, } \\
\text { BchL/ChlL and } \\
\text { BchN/ChlN }\end{array}$ & Chloroplast & $\begin{array}{l}\text { ATP; NADPH; } \\
\text { [Fe-S] }\end{array}$ & $\begin{array}{l}\text { Anoxigenic bacteria, } \\
\text { Photos. bacteria, } \\
\text { cyanobacteria, plants } \\
\text { (except angiosperms }\end{array}$ \\
\hline $\begin{array}{c}\text { LPOR } \\
\text { (EC 1.3.1.33) }\end{array}$ & Insensitive & Dependent & $\begin{array}{l}\text { (isoforms):por } A \text {, } \\
\text { por } B \text { and por } C\end{array}$ & Nucleus & $\mathrm{NADPH}$ & $\begin{array}{l}\text { cyanobacteria and } \\
\text { plants }\end{array}$ \\
\hline
\end{tabular}

photosynthetic organisms to maintain a high level of $C h l$ biosynthesis under distinct and changing conditions in their environment [67]. The reductions made by $L P O R$, and BciA (DVR) enzymes occur in the former process with $N A D P H$ as a hydride-donating cofactor (Table 1), while DPOR, BciB (DVR) and COR enzymes catalyze the reduction through the latter process with ferrodoxin enzymatically reduced by $N A D P H$ as an electron donor [68]. After analyze at all the characteristics mentioned before, the comparison between these four enzymes shows that the $L P O R$ is the one that has the less similarities related to the rest of this group (Table 1). LPOR is the most distinct according to the multiple sequence alignment with the other enzymes (DPOR, COR and $D V R)$ which are closely related when comparing with each other. They have several characteristics in common (Table 1).

\subsection{Comparisons between These Enzymes and Nitrogenase}

Nitrogenase (dinitrogenase) is a complex enzyme responsible for biological nitrogen fixation which converts the atmospheric dinitrogen $\left(\mathrm{N}_{2}\right)$ into ammonia $\left(\mathrm{NH}_{3}\right)$ [69]-[71], in $\mathrm{N}_{2}$-fixing organisms (diazotrophs). A typical nitrogenase is an $\alpha_{2} \beta_{2}$ tetramer encoded by $\mathrm{NifH}, \mathrm{NifD}$ and $\mathrm{NifK}$ and containing an iron-molybdenum cofactor, FeMoCo [72] [73]. Nitrogenase is an enzyme that is divided into two protein complexes, oneisFe-protein, which is an ATP-dependent reductase specific for the MoFe-protein and also carries one 4Fe-4S cluster bridged between these two complexes. The other complex is theMoFe-protein, which provides the catalytic centers. It has two types of metalloclusters: the P-cluster (an [8Fe-7S] cluster) and the FeMo-cofactor comprising 1Mo-7Fe9S-X homocitrate. The Fe-protein is reduced by ferredoxin or flavodoxin and then the electrons are transferred from the [4Fe-4S] cluster of the Fe-protein to the FeMo-cofactor of the MoFe-protein via the P-cluster. The enzymes DPOR and COR (Table 1) are considered twonitrogenase-like enzymes because they share significant amino acid sequence homology to the corresponding subunits of nitrogenase. Whereas subunits BchL/ChlL, $B c h X$ and NifH exhibit a sequence identity at the amino acid level of 33\%, subunits BchN/ChlN, BchY, NifD, and $B c h B / C h l B, B c h Z$, and NifK, respectively, show lower sequence identities of $15 \%$. The DPOR's NB-protein shows more similarity with the nitrogenase homologous MoFe protein (a NifD-NifK heterotetramer) of nitrogenase [23] [31] [40] [43] [44] [46] [47] [53] [74], contrarly, the L-protein (DPOR) is most structurally related to Fe-protein (a NifH homodimer) (33\% identity and 50\% similarity) [44]. Other authors [23] [33] [40] [43] [44] [60] discovered more cases of significant similarities between them such as all of them are dependent on the presence of ATP and reductant dithionite. Nomata et al. [23] showed that the in vitro assay catalytic mechanism of COR strongly resembles DPOR catalysis. $X$-ray crystallographic, electron paramagnetic resonance, mutagenesis studies and sequencing analysis showed more indepth information about the structure of some of theseenzymes, confirming some mentioned above and new ones. For example the $N$ and $B$ proteins (DPOR) have shown that they do not have the requisite number of conserved Cys to assemble a P-cluster or the FeMo cofactor of the nitrogenase NifK and NifD heterotetramer. Instead, the conserved Cys arrangement in ChlN/BchN and ChlB/ $B c h B$ seems to be more consistent with a cluster similar to the one found in the nitrogenase accessory proteins NifE and NifN [44]. These Cys residuesligate the intra subunit 4Fe-4S cluster, that is chelated by the two protomers of L-protein [40]. These Cysresidues are also conserved in $C h l L / B c h L$ what also happen to the nitrogenase $\mathrm{NifH}$ dimer [44] [45]. In all the nitrogenase iron protein's sequences and in $b c h X$, the position 100 is occupied by an Arginine $(R)$ residue and in both BChl and ChlL it is Tyrosine $(Y)$ [13]. The Tyr ${ }_{127}$ is found conserved in all Bchl and Chl proteins, whereas the nitrogenase system, as well as the COR system makes use of an Arginine 
at the identical position [49]. These similarities happens because DPOR has evolved from ancestral genes common to nitrogenase and is distributed among anoxygenic photosynthetic bacteria, cyanobacteria, Chlorophytes, Pteridophytes, Bryophytes, and Gymnosperms, which until now has made them carry a lot of similarities [13] [75]. Another feature that Nitrogenase, COR and DPOR have is the oxygen sensitivity (Table 1), which can be irreversibly destructed by oxygen [40]. Through the evolutionary tree of the organisms, besides the fact of some domains being kept highly conserved [44] [45] [49], the DPOR have got smooth changes with the time, which in future can decrease significantly its oxygen sensibility, but still, the electrons from the [4Fe-4S] cluster of $B c h N B / C h I N B$, that are transferred directly onto the Pchlide substrate at the active site of DPOR [49], a reaction that is potentially dangerous under oxygen-rich conditions because of the substrate radical that would be a source of reactive oxygen species that would cause severe damage to cells [40]. The rapid rise in global oxygen level may have also driven the evolution of heterocysts to protect nitrogenase from oxygen, that when reaches levels over $0.3 \%(\mathrm{v} / \mathrm{v})$, the "Pasteur point", considered the level above which the activity of DPOR is functionally insufficient, and the LPOR becomes essential to survive, in the organisms that have both DPOR and LPOR [66] [76] [77]. Some species, as cyanobacteria, to cope with environmental generated reactive oxygen specieshave developed effective protection mechanisms such as catalases, peroxidases, superoxide dismutases, A-type flavor proteins (Flv1 and Flv3) [66] An example, in Cynechocystis sp. PCC6803 which are essential for photoreduction of oxygen to water and are probable candidates for the DPOR protection machinery and these mechanisms are believed to protect not only L-protein but also NB-protein from oxygen, upon exposure to air, where the gradual decrease in activity of purified NB-protein is much slower than that of L-protein [77]. DPOR seems to have become dependent on the protection mechanism rather than evolved to acquire oxygen tolerance, so, the presence of such mechanisms to protect DPOR could contribute to the evolutionary persistence of DPOR in oxygenic photosynthetic organisms. DPOR no longer operates in conditions where oxygenic photosynthesis is very active and cellular oxygen levels are very high [66].

\section{Methods}

The amino acid sequences were obtained from the NCBI's online Protein database using the respective name of each subunit or each enzyme. All the names that are mentioned for each enzyme were used, to get the maximum number of sequences, and then the Protein-Protein Basic Local Alignment Sequence Tool (BLASTP) analysis was used to get even more similar sequences, where only the entries with more that $60 \%$ similarity were taken. Then all sequences from each enzyme were compared and the repeated ones were excluded, having only one exemplar of each subunit and stored in their respective group. Then the sequences were compared within subunit, within enzyme and also different enzymes were then compared with each other to get and confirm motifs that were already referenced in the literature. The sequence alignments were made with ClustleW, and then were made into trees using the Maximum Likelihood tool. Phylogenetic and molecular evolutionary analyses were conducted using the software: Molecular Evolutionary Genetics Analysis (MEGA) version 6 [78]. The tree tools were configurated to consider significantly better at 95\% confidence $(\mathrm{P}<0.05)$ [13]. Then the tree were analysed, and compared.

\section{Conclusion}

In this paper were confirmed the similarities between $D P O R, D V R$ and $C O R$ are higher than $L P O R$, and specifically related to the subunits, the sub unit $B$ of $D P O R$ is highly similar with the sub unit $Z(C O R)$, also $L(D P O R)$ is highly similar with $X(C O R)$ and $N(D P O R)$ and $Y(C O R)$ also has high similarity, showing that COR and DPOR are the enzymes with higher similarities between these enzymes studied in this paper.

\section{References}

[1] Blankenship, R.E. (1992) Origin and Early Evolution of Photosynthesis. Photosynthesis Research, 33, 91-111. http://link.springer.com/article/10.1007/BF00039173 http://dx.doi.org/10.1007/BF00039173

[2] Olson, J.M. and Blankenship, R.E. (2004) Thinking about the Evolution of Photosynthesis. Photosynthesis Research, 80, 373-386. http://www.ncbi.nlm.nih.gov/pubmed/16328834 http://dx.doi.org/10.1023/B:PRES.0000030457.06495.83

[3] Von Wettstein, D., Gough, S. and Kannangara, C.G. (1995) Chlorophyll Biosynthesis. The Plant Cell, 7, $1039-1057$. 
http://www.ncbi.nlm.nih.gov/pmc/articles/PMC160907/pdf/071039.pdf http://dx.doi.org/10.1105/tpc.7.7.1039

[4] Golbeck, J.H. (1993) Shared Thematic Elements in Photochemical Reaction CENTERS. Proceedings of the National Academy of Sciences of the United States of America, 90, 1642-1646.

http://www.ncbi.nlm.nih.gov/pmc/articles/PMC45935/ http://dx.doi.org/10.1073/pnas.90.5.1642

[5] Allen, J.P. and Williams, J.C. (1998) Photosynthetic Reaction Centers. FEBS Letters, 438, 5-9. http://onlinelibrary.wiley.com/doi/10.1016/S0014-5793\%2898\%2901245-9/epdf http://dx.doi.org/10.1016/S0014-5793(98)01245-9

[6] Nazir, S. and Khan, M.S. (2013) Integration of Novel Chlorophyll Genes from Black Pine into the Chloroplast Genome of Tobacco. Pakistan Journal of Botany, 45, 595-600.

[7] Green, B.R., Parson, W.W. and Anderson, J.M. (2004) Photosynthetic Membranes and Their Light-Harvesting Antennas. In: Green, B.R. and Parson, W.W., Eds., Light-Harvesting Antennas in Photosynthesis, Springer, Dordrecht, 1-28.

[8] Grimm, B., Porra, R.J., Rüdiger, W., Scheer, H., Melkozernov, A.N. and Blankenship, R.E. (2006) Chlorophylls and Bacteriochlorophylls: Biochemistry, Biophysics, Functions and Applications. In: Grimm, B., Porra, R.J., Rüdiger, W. and Scheer, H., Eds., Advances in Photosynthesis and Respiration, Springer, Dordrecht, 397-412.

https://www.researchgate.net/publication/33027242_Chlorophylls_and_Bacteriochlorophylls_Biochemistry_Biophysic s Functions and Applications http://dx.doi.org/10.1007/1-4020-4516-6

[9] Rebeiz, C.A., Ioannides, I.M., Kolossov, V. and Kopetz, K.J. (1999) Chloroplast Biogenesis 80. Proposal of a Unified multibranched Chlorophyll a/b Biosynthetic Pathway. Photosynthetica, 36, 117-128. http://rd.springer.com/article/10.1023\%2FA\%3A1007027005903

[10] Bauer, C.E., Bolllvar, D.W. and Suzukl, J.Y. (1993) Genetic Analyses of Photopigment Biosynthesis in Eubacteria: A Guiding Light for Algae and Plants. Journal of Bacteriology, 175, 3919-3925. http://www.ncbi.nlm.nih.gov/pmc/articles/PMC204818/pdf/jbacter00055-0013.pdf

[11] Bollivar, D.W., Suzukl, J.Y., Beatty, J.T., Dobrowolskl, J.M. and Bauer, C.E. (1994) Directed Mutational Analysis of Bacteriochlorophyll a Biosynthesis in Rhodobacter capsulatus. Journal of Molecular Biology, 237, 622-640.

[12] Castelfranco, P., Walker, C.J. and Welnsteln, J. (1994) Biosynthetic Studies on Chlorophylls: From Protoporphyrin IX to Protochlorophyllide. In: Chadwick, D.J. and Ackrill, K., Eds., The Biosynthesis of the Tetrapyrrole Pigments, Ciba Foundation Symposium 180, John Wiley and Sons, Chichester, England, 194-204. http://onlinelibrary.wiley.com/doi/10.1002/9780470514535.ch11/summary

[13] Burke, D.H., Hearst, J.E. and Sidow, A. (1993) Early Evolution of Photosynthesis: Clues from Nitrogenase and Chlorophyll Iron Proteins. Proceedings of the National Academy of Sciences of the United States of America, 90, 7134-7138. http://dx.doi.org/10.1073/pnas.90.15.7134

[14] Nasrulhaq-Boyce, A., Griffiths, W.T. and Jones, O.T.G. (1987) The Use of Continuous Assays to Characterize the Oxidative Cyclase That Synthesizes the Chlorophyll Isocyclic Ring. Biochemical Journal, 243, 23-29.

http://www.biochemj.org/content/243/1/23 http://dx.doi.org/10.1042/bj2430023

[15] Simon, R., Priefer, U. and Pühler, A. (1983) A Broad Host Range Mobilization System for In Vivo Genetic Engineering: Transposon Mutagenesis in Gram Negative Bacteria. Nature Biotechnology, 1, 784-791. http://www.nature.com/nbt/journal/v1/n9/full/nbt1183-784.html http://dx.doi.org/10.1038/nbt1183-784

[16] Canniffe, D.P., Jackson, P.J., Hollingshead, S., Dickman, M.J. and Hunter, C.N. (2013) Identification of an 8-Vinyl reductase Involved in Bacteriochlorophyll Biosynthesis in Rhodobacter sphaeroides and Evidence for the Existence of a Third Distinct Class of the Enzyme. Biochemical Journal, 450, 397-405.

http://www.ncbi.nlm.nih.gov/pubmed/23252506 http://dx.doi.org/10.1042/BJ20121723

[17] Canniffe D.P., Chidgey J.W. and Hunter, C.N. (2014) Elucidation of the Preferred Routes of C8-Vinyl Reduction in Chlorophyll and Bacteriochlorophyll Biosynthesis. Biochemical Journal, 462, 433-440. http://dx.doi.org/10.1042/BJ20140163

[18] Tripathy, B.C. and Rebeiz, C.A. (1988) Chloroplast Biogenesis 60 : Conversion of Divinyl Protochlorophyllide to Monovinyl Protochlorophyllide in Green(Ing) Barley, a Dark Monovinyl/Light Divinyl Plant Species. Plant Physiology, 87, 89-94. http://www.ncbi.nlm.nih.gov/pmc/articles/PMC1054704/ http://dx.doi.org/10.1104/pp.87.1.89

[19] Griffiths, W.T. (1991) Protochlorophyllide Photoreduction. In: Scheer, H., Ed., Chlorophylls, CRC Press, Boca Raton, 433-449. 
[20] Beale, S.I. and Weinstein, J.D. (1991) Biosynthesis of 5-Aminolevulinic Acid in Phototrophic Organisms. In: Scheer, H., Ed., Chlorophylls, CRC Press, Boca Raton, 385-406.

[21] Masuda, T. and Takamiya, K. (2004) Novel Insights into the Enzymology, Regulation and Physiological Functions of Light-Dependent Protochlorophyllide Oxidoreductase in Angiosperms. Photosynthesis Research, 81, 1-29. http://www.ncbi.nlm.nih.gov/pubmed/16328844 http://dx.doi.org/10.1023/B:PRES.0000028392.80354.7c

[22] Reinbothe, C., El Bakkouri, M., Buhr, F., Muraki, N., Nomata, J., Kurisu, G., Fujita, Y. and Reinbothe, S. (2010) Chlorophyll Biosynthesis: Spotlight on Protochlorophyllide Reduction. Trends in Plant Science, 15, 614-622. http://www.sciencedirect.com/science/article/pii/S136013851000155X http://dx.doi.org/10.1016/j.tplants.2010.07.002

[23] Nomata, J., Mizoguchi, T., Tamiaki, H. and Fujita, Y. (2006) A Second Nitrogenase-Like Enzyme for Bacteriochlorophyll Biosynthesis: Reconstitution of Chlorophyllide a Reductase with Purified X-Protein (BchX) and YZ-Protein (BchY-BchZ) from Rhodobacter capsulatus. The Journal of Biological Chemistry, 281, 15021-15028. http://dx.doi.org/10.1074/jbc.M601750200

[24] Partensky, F., Hess, W.R. and Vaulot, D. (1999) Prochlorococcus, a Marine Photosynthetic Prokaryote of Global Significance. Microbiology and Molecular Biology Reviews, 63, 106-127.

[25] Islam, M.R., Aikawa, S., Midorikawa, T., Kashino, Y., Satoh, K. and Koike, H. (2008) Slr1923 of Synechocystis sp. PCC6803 Is Essential for Conversion of 3,8-Divinyl(Proto)Chlorophyll(Ide) to 3-Monovinyl(Proto)Chlorophyll(Ide). Plant Physiology, 148, 1068-1081. http://dx.doi.org/10.1104/pp.108.123117

[26] Ito, H., Yokono, M., Tanaka, R. and Tanaka, A. (2008) Identification of a Novel Vinyl Reductase Gene Essential for the Biosynthesis of Monovinyl Chlorophyll in Synechocystis sp. PCC6803. The Journal of Biological Chemistry, 283, 9002-9011. http://dx.doi.org/10.1074/jbc.M708369200

[27] Ito, H. and Tanaka, A. (2014) Evolution of a New Chlorophyll Metabolic Pathway Driven by the Dynamic Changes in Enzyme Promiscuous Activity. Plant and Cell Physiology, 55, 593-603. http://dx.doi.org/10.1093/pcp/pct203

[28] Sousa, F.L., Shavit-Grievink, L., Allen, J.F. and Martin, W.F. (2012) Chlorophyll Biosynthesis Gene Evolution Indicates Photosystem Gene Duplication, Not Photosystem Merger, at the Origin of Oxygenic Photosynthesis. Genome Biology and Evolution, 5, 200-216. http://dx.doi.org/10.1093/gbe/evs127

[29] Ogawa, T., Inoue, Y., Kitajima, M. and Shibata, K. (1973) Action Spectra for Biosynthesis of Chlorophylls A and B and B-Carotene. Photochemistry and Photobiology, 18, 229-235.

http://onlinelibrary.wiley.com/doi/10.1111/j.1751-1097.1973.tb06416.x/abstract

http://dx.doi.org/10.1111/j.1751-1097.1973.tb06416.x

[30] Wilks, H.M. and Timko, M.P. (1995) A light-Dependent Complementation System for Analysis of NADPH: Protochlorophyllide Oxidoreductase: Identification and Mutagenesis of Two Conserved Residues That Are Essential for Enzyme Activity. Proceedings of the National Academy of Sciences of the United States of America, 92, 724-728. http://www.ncbi.nlm.nih.gov/pmc/articles/PMC42692/pdf/pnas01481-0085.pdf http://dx.doi.org/10.1073/pnas.92.3.724

[31] Fujita, Y. (1996) Protochlorophyllide Reduction: A Key Step in the Greening of Plants. Plant and Cell Physiology, 37, 411-421. http://pcp.oxfordjournals.org/content/37/4/411.long http://dx.doi.org/10.1093/oxfordjournals.pcp.a028962

[32] Armstrong, G.A. (1998) Greening in the Dark: Light Independent Protochlorophyllide Biosynthesis from Anoxygenic Photosynthetic Bacteria to Gymnosperms. Journal of Photochemistry and Photobiology B, 43, 87-100.

http://www.sciencedirect.com/science/article/pii/S1011134498000633 http://dx.doi.org/10.1016/S1011-1344(98)00063-3

[33] Nomata, J., Kondo, T., Mizoguchi, T., Tamiaki, H., Itoh, S. and Fujita, Y. (2014) Dark-Operative Protochlorophyllide Oxidoreductase Generates Substrate Radicals by an Iron-Sulphur Cluster in Bacteriochlorophyll Biosynthesis. Scientific ReportS, 4, Article Number: 5455. http://www.nature.com/articles/srep05455 http://dx.doi.org/10.1038/srep05455

[34] Lebedev, N. and Imko, M.P. (1999) Protochlorophyllide Oxidoreductase B-Catalyzed Protochlorophyllide Photoreduction in Vitro: Insight into the Mechanism of Chlorophyll Formation in Light-Adapted Plants. Proceedings of the National Academy of Sciences of the United States of America, 96, 9954-9959. http://dx.doi.org/10.1073/pnas.96.17.9954

[35] Suzuki, J.Y., Bollivar, D.W. and Bauer, C.E. (1997) Genetic Analysis of Chlorophyll Biosynthesis. Annual Review of Genetics, 31, 61-89. http://www.annualreviews.org/doi/pdf/10.1146/annurev.genet.31.1.61 http://dx.doi.org/10.1146/annurev.genet.31.1.61

[36] Sytina, O.A., Heyes, D.J., Hunter, C.N., Alexandre, M.T., van Stokkum, I.H., van Grondelle, R. and Groot, M.L. (2008) Conformational Changes in an Ultrafast Light-Driven Enzyme Determine Catalytic Activity. Nature, 456, 1001-1004. 
http://dx.doi.org/10.1038/nature07354

[37] Suzuki, J.Y. and Bauer, C.E. (1995) A Prokaryotic Origin for Light-Dependent Chlorophyll Biosynthesis of Plants. Proceedings of the National Academy of Sciences of the United States of America, 92, 3749-3753. http://www.ncbi.nlm.nih.gov/pmc/articles/PMC42039/ http://dx.doi.org/10.1073/pnas.92.9.3749

[38] Yang, J. and Cheng, Q. (2004) Origin and Evolution of the Light-Dependent Protochlorophyllide Oxydoreductase (LPOR) Genes. Plant Biology, 6, 537-544. http://www.ncbi.nlm.nih.gov/pubmed/15375724 http://dx.doi.org/10.1055/s-2004-821270

[39] Galperin, M.Y., Walker, D.R. and Koonin, E.V. (1998) Analogous Enzymes: Independent Inventions in Enzyme Evolution. Genome Research, 8, 779-790. http://genome.cshlp.org/content/8/8/779.long http://dx.doi.org/10.1016/j.febslet.2006.10.014

[40] Nomata, J., Kitashima, M., Inoue, K. and Fujita, Y. (2006) Nitrogenase Fe Protein Like Fe-Scluster Is Conserved in L-Protein (Bchl) of Dark-Operative Protochlorophyllide Reductase from Rhodobacter capsulatus. FEBS Letters, 580, 6151-6154. http://www.sciencedirect.com/science/article/pii/S0014579306012208 http://dx.doi.org/10.1016/j.febslet.2006.10.014

[41] Yang, Z.M. and Bauer, C.E. (1990) Rhodobacter capsulatus Genes Involved in Early Steps of the Bacteriochlorophyll Biosynthetic Pathway. Journal of Bacteriology, 172, 5001-5010. http://jb.asm.org/content/172/9/5001.long

[42] Burke, D.H., Alberti, M. and Hearst, J.E. (1993) bchFNBH Bacteriochlorophyll Synthesis Genes of Rhodobacter capsulatus and Identification of the Third Subunit of Light-Independent Protochlorophyllide Reductase in Bacteria and Plants. Journal of Bacteriology, 175, 2414-2422. http://www.ncbi.nlm.nih.gov/pmc/articles/PMC204531/

[43] Fujita, Y. and Bauer, C.E. (2000) Reconstitution of Light-Independent Protochlorophyllide Reductase from Purified Bacteriochlorophyll and BchN-BchB Subunits-In Vitro Confirmation of Nitrogenase-Like Features of a Bacteriochlorophyll Biosynthesis Enzyme. The Journal of Biological Chemistry, 275, 23583-23588.

http://www.jbc.org/content/275/31/23583.long http://dx.doi.org/10.1074/jbc.M002904200

[44] Nomata, J., Swem, L.R., Bauer, C.E. and Fujita, Y. (2005) Overexpression and Characterization of Dark-Operative Protochlorophyllide reductase from Rhodobacter capsulatus. Biochimica et Biophysica Acta, 1708, 229-237. http://www.sciencedirect.com/science/article/pii/S0005272805000794 http://dx.doi.org/10.1016/j.bbabio.2005.02.002

[45] Muraki, N., Nomata, J., Ebata, K., Mizoguchi, T., Shiba, T., Tamiaki, H., Kurisu, G. and Fujita, Y. (2010) X-Ray Crystal Structure of the Light-Independent Protochlorophyllide Reductase. Nature, 465, 110-114. http://www.nature.com/nature/journal/v465/n7294/full/nature08950.html http://dx.doi.org/10.1038/nature08950

[46] Fujita, Y. and Bauer, C.E. (2003) The Light-Independent Protochlorophyllide Reductase: A Nitrogenase-Like Enzyme Catalyzing a Key Reaction for Greening in the Dark. In: Kadish, K., Smith, K.M. and Guilard, R., Eds., Chlorophylls and Bilins: Biosynthesis, Synthesis and Degradation. Academic Press, Amsterdam, 109-156. https://www.researchgate.net/publication/277670730 The Light-Independent Protochlorophyllide Reductase A Nitr ogenase-Like_Enzyme_Catalyzing_a_Key_Reaction_for_Greening_in_the_Dark http://dx.doi.org/10.1016/b978-0-08-092387-1.50010-2

[47] Nomata, J., Ogawa, T., Kitashima, M., Inoue, K. and Fujita, Y. (2008) Loss of Oocytes Due to Conditional Ablation of Murine Double Minute $2(M d m 2)$ Gene Is p53-Dependent and Results in Female Sterility. FEBS Letters, 582, 13461350. http://linkinghub.elsevier.com/retrieve/pii/S0014-5793(08)00247-0 http://dx.doi.org/10.1016/j.febslet.2008.03.018

[48] Xiong, J., Inoue, K. and Bauer, C.E. (1998) Tracking Molecular Evolution of Photosynthesis by Characterization of a Major Photosynthesis Gene Cluster from Heliobacillus mobilis. Proceedings of the National Academy of Sciences of the United States of America, 95, 14851-14856. http://www.ncbi.nlm.nih.gov/pmc/articles/PMC24539/ http://dx.doi.org/10.1073/pnas.95.25.14851

[49] Wätzlich, D., Bröcker, M.J., Uliczka, F., Ribbe, M., Virus, S., Jahn, D., et al. (2009) Chimeric Nitrogenase-Like Enzymes of (Bacterio) Chlorophyll Biosynthesis. The Journal of Biological Chemistry, 284, 15530-15540. http://www.jbc.org/content/284/23/15530.full http://dx.doi.org/10.1074/jbc.M901331200

[50] Ohyama, K., Kohchi, T., Sano, T. and Yamada, Y. (1988) Newly Identified Groups of Genes in Chloroplasts. Trends in Biochemical Sciences, 13, 19-22. http://www.cell.com/trends/biochemical-sciences/abstract/0968-0004(88)90013-8 http://dx.doi.org/10.1016/0968-0004(88)90013-8

[51] Suzuki, J.Y. and Bauer, C.E. (1992) Light-Independent Chlorophyll Biosynthesis: Involvement of the Chloroplast Gene chlL (frxC). Plant Cell, 4, 929-940. http://www.ncbi.nlm.nih.gov/pmc/articles/PMC160185/pdf/040929.pdf 
http://dx.doi.org/10.1105/tpc.4.8.929

[52] Yamada, K., Matsuda, M., Fujita, Y., Matsubara, H. and Sugai, M. (1992) A frxC Homologue Exists in the Chloroplast DNAs from Various Pteridophytes and Gymnosperms. Plant and Cell Physiology, 33, 325-327. http://pcp.oxfordjournals.org/content/33/3/325.abstract

[53] Burke, D.H., Raubeson, L.A., Alberti, M., Hearst, J.E., Jordan, E.T., Kirch, S.A., Valinski, A.E.C., Conant, D.S. and Stein, D.B. (1993) The chlL (frxC) Gene: Phylogenetic Distribution in Vascular Plants and DNA Sequence from Polystichum acrostichoides (Pteridophyta) and Synechococcus sp. 7002 (Cyanobacteria). Plant Systematics and Evolution, 187, 89-102. http://rd.springer.com/article/10.1007\%2FBF00994092 http://dx.doi.org/10.1007/BF00994092

[54] Ji, H.W., Tang, C.Q., Li, L.B. and Kuang, T.Y. (2001) Photosynthesis Development in Dark-Grown Lotus (Nelumbo nucifera) Seedlings. Acta Botanica Sinica, 43, 1129-1133.

[55] Chen, M. (2014) Chlorophyll Modifications and Their Spectral Extension in Oxygenic Photosynthesis. Annual Review of Biochemistry, 83, 19-41. http://dx.doi.org/10.1146/annurev-biochem-072711-162943

[56] Kusumi, J., Sato, A. and Tachida, H. (2006) Relaxation of Functional Constraint on Light-Independent Protochlorophyllide Oxidoreductase in Thuja. Molecular Biology and Evolution, 23, 941-948.

http://mbe.oxfordjournals.org/content/23/5/941.full http://dx.doi.org/10.1093/molbev/msj097

[57] Fujita, Y., Takahashi, Y., Kohchi, T., Ozeki, H., Ohyama, K. and Matsubara, H. (1989) Identification of a Novel nifHLike (frxC) Protein in Chloroplasts of the Liverwort Marchantia polymorpha. Plant Molecular Biology, 13, 551-561. http://link.springer.com/article/10.1007\%2FBF00027315 http://dx.doi.org/10.1007/BF00027315

[58] Liu, X.Q., Xu, H. and Huang, C. (1993) Chloroplast ChlB Gene Is Required for Light-Independent Chlorophyll Accumulation in Chlamydomonas reinhardtii. Plant Molecular Biology, 23, 297-308.

http://www.ncbi.nlm.nih.gov/pubmed/8219066 http://dx.doi.org/10.1007/BF00029006

[59] Page, C.C., Moser, C.C., Chen, X. and Dutton, P.L. (1999) Natural Engineering Principles of Electron Tunneling in Biological Oxidation-Reduction. Nature, 402, 47-52. http://www.nature.com/nature/journal/v402/n6757/full/402047a0.html

[60] Bröcker, M.J., Schomburg, S., Heinz, D.W., Jahn, D., Schubert, W.-D. and Moser, J. (2010) Crystal Structure of the Nitrogenase-Like Dark Operative Protochlorophyllide Oxidoreductase Catalytic Complex $(\text { ChlN/ChlB })_{2}$. The Journal of Biological Chemistry, 285, 27336-27345. http://www.jbc.org/content/285/35/27336.long http://dx.doi.org/10.1074/jbc.M110.126698

[61] Moser, J., Lange, C., Krausze, J., Rebelein, J., Schubert, W.D., Ribbe, M.W., Heinz, D.W. and Jahn, D. (2013) Structure of ADP-Aluminium Fluoride-Stabilized Protochlorophyllide Oxidoreductase Complex. Proceedings of the National Academy of Sciences of the United States of America, 110, 2094-2098. http://dx.doi.org/10.1073/pnas.1218303110

[62] Tsukatani, Y., Yamamoto, H., Harada, J., Yoshitomi, T., Nomata, J., Kasahara, M., Mizoguchi, T., Fujitam, Y and Tamiaki, H. (2013) An Unexpectedly Branched Biosynthetic Pathway for Bacteriochlorophyll $\beta$ Capable of Absorbing Near-Infrared Light. Scientific Reports, 3, 1217-1223. http://dx.doi.org/10.1038/srep01217

[63] Hanada, S., Takaichi, S., Matsuura, K. and Nakamura, K. (2002) Roseiflexus castenholzii gen. nov., sp. nov., a Thermophilic, Filamentous, Photosynthetic Bacterium Which Lacks Chlorosomes. International Journal of Systematic and Evolutionary Microbiology, 52, 187-193. http://dx.doi.org/10.1099/00207713-52-1-187

[64] Tsukatani, Y., Arada, J., Nomata, J., Yamamoto, H., Fujita, Y., Mizoguchi, T. and Tamiaki, H. (2015) Rhodobacter sphaeroides Mutants Overexpressing Chlorophyllide $\alpha$ Oxidoreductase of Blastochloris viridis Elucidate Functions of Enzymes in Late Bacteriochlorophyll Biosynthetic Pathways. Scientific Reports, 5, Article Number: 9741.

http://www.nature.com/articles/srep09741 http://dx.doi.org/10.1038/srep09741

[65] Burke, D.H., Alberti, M. and Hearst, J.E. (1993) The Rhodobacter capsulatus Chlorin Reductase-Encoding Locus, bchA, Consists of Three Genes, bchX, bchY, and bchZ. Journal of Bacteriology, 175, 2407-2413. http://www.ncbi.nlm.nih.gov/pubmed/8468299

[66] Yamazaki, S., Nomata, J. and Fujita, Y. (2006) Differential Operation of Dual Protochlorophyllide Reductases for Chlorophyll Biosynthesis in Response to Environmental Oxygen Levels in the Cyanobacterium Leptolyngbyaboryana. Plant Physiology, 142, 911-922. http://dx.doi.org/10.1104/pp.106.086090

[67] Shui, J., Saunders, E., Needleman, R., Nappi, M., Cooper, J., Hall, L., Kehoe, D. and Stowe-Evans, E. (2009) LightDependent and Light-Independent Protochlorophyllide Oxidoreductases in the Chromatically Adapting Cyanobacterium Fremyella diplosiphon UTEX 481. Plant and Cell Physiology, 50, 1507-1521. 
http://pcp.oxfordjournals.org/content/50/8/1507.long http://dx.doi.org/10.1093/pcp/pcp095

[68] Tamiaki, H., Teramura, M. and Tsukatani, Y. (2015) Reduction Processes in Biosynthesis of Chlorophyll Molecules: Chemical Implication of Enzymatically Regio- and Stereoselective Hydrogenations in the Late Stages of Their Biosynthetic Pathway. Bulletin of the Chemical Society of Japan, 89, 161-173. https://www.jstage.jst.go.jp/article/bcsj/advpub/0/advpub_20150307/_article http://dx.doi.org/10.1246/bcsj.20150307

[69] Wittenberg, J.B., Appleby, C.A., Bergersen, F.J. and Turner, G.L. (1877) Leghemoglobin: The Role of Hemoglobin in the Nitrogen-Fixing Legume Root Nodule. Annals of the New York Academy of Sciences, 244, 28-34. http://dx.doi.org/10.1111/j.1749-6632.1975.tb41519.x

[70] Cheng, Q. (2008) Perspectives in Biological Nitrogen Fixation Research. Journal of Integrative Plant Biology, 50, 784796. http://www.ncbi.nlm.nih.gov/pubmed/18713389 http://dx.doi.org/10.1111/j.1744-7909.2008.00700.x

[71] Cheng, Q, Zhang, Y., Sun, W.L., Liu, G.X., Li, M.Z., Li, Y.N., Yan, Y.L. and Lin, M. (2014) How Prokaryotic Microbes Fix Nitrogen? Current Trends in Microbiology, 9, 19-34. http://www.researchtrends.net/tia/abstract.asp?in=0\&vn=9\&tid=41\&aid=5573\&pub=2014\&type

[72] Yates, M.G. (1992) The Enzymology of Molybdenum-Dependent Nitrogen Fixation. In: Stacey, G., Burris, R.H. and Evans, H.J, Eds., Biological Nitrogen Fixation, Chapman and Hall, New York, 685-735.

[73] Igarashi, R.Y. and Seefeldt, L.C. (2003) Nitrogen Fixation: The Mechanism of the Mo-Dependent Nitrogenase. Critical Reviews in Biochemistry and Molecular Biology, 38, 351-384. http://dx.doi.org/10.1080/10409230391036766

[74] Kim, C.-H. and Rees, D.C. (1992) Structural Models for the Metal Centers in the Nitrogenase Molybdenum-Iron Protein. Science, 257, 1677-1682. http://www.sciencemag.org/content/257/5077/1677.long http://dx.doi.org/10.1126/science.1529354

[75] Raymond, J., Siefert, J.L., Staples, C.R. and Blankenship, R.E. (2004) The Natural History of Nitrogen Fixation. Molecular Biology and Evolution, 21, 541-554. http://mbe.oxfordjournals.org/content/21/3/541.full.pdf + html http://dx.doi.org/10.1093/molbev/msh047

[76] Fujita, Y., Takagi H. and Hase T. (1998) Cloning of the Gene Encoding a Protochlorophyllide Reductase: The Physiological Significance of Co-Existence of Light-Dependent and -Independent Protochlorophyllide Reduction Systems in the Cyanobacterium Pleconema boryanum. Plant and Cell Physiology, 39, 177-185. http://dx.doi.org/10.1093/oxfordjournals.pcp.a029355

[77] Yamamoto, H., Nomata, J. and Fujita, Y. (2008) Functional Expression of Nitrogenase-Like Protochlorophyllide Reductase from Rhodobacter capsulatus in Escherichia coli. Photochemical \& Photobiological Sciences, 7, 1238-1242. http://pubs.rsc.org/en/content/articlepdf/2008/pp/b802427h http://dx.doi.org/10.1039/b802427h

[78] Tamura, K., Stecher, G., Peterson, D., Filipski, A. and Kumar, S. (2013) MEGA6 Molecular Evolutionary Genetics Analysis Version 6.0. Molecular Biology and Evolution, 30, 2725-2729. http://www.kumarlab.net http://dx.doi.org/10.1093/molbev/mst197

\section{Submit or recommend next manuscript to SCIRP and we will provide best service for you:}

Accepting pre-submission inquiries through Email, Facebook, LinkedIn, Twitter, etc.

A wide selection of journals (inclusive of 9 subjects, more than 200 journals)

Providing 24-hour high-quality service

User-friendly online submission system

Fair and swift peer-review system

Efficient typesetting and proofreading procedure

Display of the result of downloads and visits, as well as the number of cited articles

Maximum dissemination of your research work

Submit your manuscript at: http://papersubmission.scirp.org/ 